Journal of Education and Vocational Research

Vol. 4, No. 8, pp. 238-245, Aug 2013 (ISSN 2221-2590)

\title{
Learning Environment, Students' Attitude and Performance in Quantitative Course Units: A Focus on Business Students
}

\author{
Freddie Semukono, ${ }^{*}$ Laura A. Orobia, Alice Arinaitwe \\ Makerere University Business School, Uganda \\ *lorobia@mubs.ac.ug
}

\begin{abstract}
This study examines the persistent poor performance in quantitative course units amongst undergraduate business students, using the case of Makerere University Business School. The data were collected from 346 third year students using a face-to-face administered questionnaire survey; and analysed using descriptive statistics, correlation and hierarchical regression analyses. The findings indicate that while learning environment and students' attitude are positively associated with performance in quantitative courses, students' attitude towards quantitative courses causes more variations in performance. Paucity of studies on performance in quantitative business courses deprived the study of the opportunity to cross validate the findings. Future studies should be conducted to confirm the results. Management of universities should consider learning environment and students' attitude when determining possible changes to enhance students' performance in quantitative courses. This study extends the predominantly mathematics studies to other business quantitative courses at university level.
\end{abstract}

Keywords: Learning environment, attitude and academic performance

\section{Introduction}

In this study, we extend the predominantly mathematics studies to other quantitative courses at university level. Specifically, we investigate the relationship between learning environment, students' attitude and performance in quantitative courses. Considering the current condition in the job market characterised by increasing competition, the role of competence at the gate cannot be overemphasized. Competence, which is viewed in terms of knowledge, skill and abilities gained during the term on a program, is believed to be a reflection of academic performance (Beswick, 2006). Anecdotal evidence indicates that employers today emphasize the importance of good academic grades for various job positions. Consequently, universities around the globe are under pressure to adopt strategies that will enable them generate competitive graduates for the job market. This implies the need to understand the factors that enhance academic performance of university students. Previous researches have investigated the impact of factors such as age, gender, class standing, and entry requirements on students' performance in business programmes (Arbaugh, 2000; Schwartz \& Hanson, 2006). However, the studies focus on the overall academic performance, thus paying less attention to details of individual course units such as quantitative course units (quantitative methods, business statistics and accounting). Moreover, performance in individual course units affects the overall academic performance. The few studies that have examined specific course units have tended to concentrate on college students' performance in mathematics (Beswick, 2006; Uusimaki \& Nason, 2004; Wilkins \& Brand, 2004). Consequently, little is known about university students. Furthermore, there is insufficient knowledge on the impact of learning environment and students' attitude on performance in quantitative course units, in a developing country like Uganda.

Learning environment refers to the whole range of components and activities within which learning takes place (Sternberg \& Kaufman, 1998). It takes the form of teacher characteristics, teaching characteristics and classroom characteristics. Previous studies have used these factors separately to explain overall academic performance and performance in mathematics. Attitude on the other hand is defined as the like or dislike of a course/subject. Students' attitudes have been considered an important factor in influencing participation and success in various courses (Popham, 2005). Previous studies demonstrate that students' attitudes affect how they approach, persist, and perform in a subject (see Popham, 2005). Based on these insights, performance in quantitative course units at university may be explained by the existing learning environment and students' 
attitude. Therefore, this study investigates this link. Most business programmes (Bachelors of Business Administration; Commerce; Business Computing; Human Resource Management; Entrepreneurship and Small Business Management; Procurement and Logistic Management and Leisure and Hospitality Management) have quantitative courses. The courses include statistics, accounting, financial management and quantitative methods among others. Empirical evidence from Makerere University Business School (MUBS) indicates that students tend to perform poorly in quantitative courses. In this regard, MUBS management and the students' body have developed strategies that include but are not limited to tutorials and study clinics to improve academic performance. However, despite the various efforts, the situation is still alarming (students' results database, 2009). A situation if left unchecked will affect the competitiveness of MUBS students in the job market. Furthermore, poor academic performance leads to a student having low self-esteem and causes stress on the parents. We expect that when the causes of the persistent poor performance in quantitative courses are understood, it is easier to propose solutions and policies to enhance performance. Besides, identification of poor performance in quantitative courses and execution of corrective action is imperative.

This study seeks to contribute in a number of ways. The findings will help academicians in theory development to explain academic performance. Second, the findings are important for university managers who want to determine the possible required changes to improve performance in quantitative courses. Third, policy makers may use the findings in curriculum development for institutions of higher education in their effort to improve performance in quantitative subjects. This study was guided by following research objectives:

- $\quad$ To examine the relationship between learning environment and performance in quantitative course units at MUBS

- $\quad$ To examine the relationship between students' attitude towards quantitative and performance in course units at MUBS

The rest of the paper is structured as follows. We begin with previous studies on academic performance. The next section covers past studies on learning environment and student's attitude. This is followed by methods employed in collecting and analyzing the data. Results and discussion are then presented. In the last section, conclusions and implications for academics, practitioners and policy makers are presented.

\section{Literature Review}

Previous studies on academic performance: Academic performance continues to be a major concern amongst academicians, researchers and policy makers. Strictly speaking, the persistent poor performance especially in quantitative courses is alarming. In this regard, the marketability of graduates in put on the line, as such, something needs to be done to correct this phenomenon. Most studies have tended to focus on investigating academic performance in general (Barnard, 2004; Roberts, 2007; Shafiq et al., 2011). Others that have examined performance in individual courses concentrate on performance in mathematics (Maliki, Ngban \& Ibu, 2009), thus paying less attention to other quantitative courses at university level such as statistics, quantitative techniques, accounting and financial management. Nevertheless, extant literature highlights a number of factors that affect students' characteristics and their environment, teacher characteristics and background, teaching style and materials. In addition, academic performance is widely measured in terms of grades and test scores (Kingdon, 2006; Rockoff, 2003). Considering all the possible variables that explain academic performance in general, this study focuses on learning environment and attitude towards quantitative courses at university level. In the next section, we present a brief discussion of previous studies.

Learning environment: Learning environment encompasses lecturer, lecturing and classroom characteristics. On the effect of facilitators' characteristics, Goldhaber (2002) and Sanders (2000) assert that such factors as educational attainment, years of teaching experience, or the degree of teacher involvement in professional development activities play a role in students' academic performance. In that, teachers who possess such characteristics are associated with full preparation to impart knowledge. Hammond (2000) add that, teachers joining the education environment without full preparation lack planning skills and ability to implement instruction, when compared to those who are fully prepared. In support, Trei (2005) asserts that 
students consistently perform better when taught by certified teachers who have received methodological training. More still, teacher's attitude, facilitation of mathematical thinking, facilitation of learning, course organisation and effective assessment have equally been found to determine academic achievement (Beswick, 2006; Hanushek, 1971; Swan et al., 2000; Wilkins \& Brand, 2004).

On the effect of teaching approach, Patriciah and Johnson (2007) report that, academic performance is enhanced by the approaches employed in imparting knowledge. This suggests that if learning quantitative courses are to be made interesting and enjoyable. One of the popular teaching approach is the teacher centred approach, which has been defined as direct teaching which emphasizing systematic sequencing of lessons, a presentation of new content and skill, guided students practice, feedback and independent practice by student (Walberg, 1999). However, this approach can only translate into effective teaching when an analytic/synthetic approach, well organized, teacher-group interaction, teacher-individual students interaction and dynamism/enthusiasm manner is employed. A modern teaching approach is the group oriented discussion approach, where students are expected to be active in their learning process by participating in discussion and or collaborative activities (Yoder \& Hachevar, 2005). Mohidin et al. (2009) found the learner centered approach to be more effective than the teacher centered approach. Felder, Felder and Dietz (2002)'s study shows that a more involving, collaborative, exploratory, adventurous, reflective and peer tutoring will enhance passion for the subject and surmount forbia.

On the effect of classroom characteristics, Wolf and Fraser (2007) assert that class size and infrastructure are primary classroom characteristics that shape learning environment. Urquiola (2006) add that learning is reduced if the classroom condition is too hot, too cold, or lacks fresh air that leaves them drowsy. Elements like day lighting and indoor air have an effect on student performance particularly if they are inadequate (Beswick, 2007). Past studies indicate that physical classroom condition affects students' performance (U.S.EPA, 2000 \& Stage, 2000). Students prefer smaller classes because such size facilitates adequate attention to each student and, therefore, favour learning to take place (Martins \& Walker 2006). This suggests that when classroom characteristics are improve, students will be comfortable, feel relaxed and this will in turn facilitate concentration and consequent academic performance. Whereas a lot has been done on the effect of learning environment on academic performance, there is insufficient evidence from African universities specifically focusing on quantitative courses at university.

Attitude towards quantitative course units: According to Fishbein and Ajzen (2010) attitudes are an expression of inner feelings that reflect whether an individual is favourably or unfavourably disposed to some 'attitude object'. Likewise, Thurstone (1928) conceptualized an attitude as a combination of an individual's evaluative judgments about a given object. The relationship between attitude and performance is founded the theory of reasoned action. According to the theory when people are favourably disposed to an object or behaviour in question, they are likely take up the object or behaviour. This is supported by Wentzel (1998) who found that interest in activities increases the likelihood that individual will formulate goals relating to that activity and invest time and effort to achieve them. With regard to academic performance, Fisher (2000) established that attitude towards mathematics affects students achievement. This means that students attitude towards quantitative subjects affect how they approach, persist, and succeed at the subject. Students with positive attitude actually value quantitative subjects, persistence and work hard towards getting better grades (Pokay \& Blumenfeld, 1990). Whereas a lot has been done on academic performance and its factors, there is still little known about the perspective of universities in developing countries in Africa. Considering all the possible variables that explain academic performance in general, this study intends to fill gaps identified by examining learning environment and attitude towards quantitative courses at university.

\section{Methodology}

This study employed a quantitative cross sectional survey design; which is pre-planned and structured, and is typically based on a large sample. The population consisted of 5,832 third year bachelor students of Makerere University Business School. Basing on this population a sample of 1,646 students was generated using the sample size determination table by Krejcie and Morgan (1970). Under a simple random sampling method, a list of third year students from the database of academic year 2009/10 was obtained and the respondents were selected using a lottery method. The specific business programmes were: 
- $\quad$ Bachelor of Business Administration (BBA),

- Bachelor of Human Resource Management (BHRM),

- $\quad$ Bachelor of Entrepreneurship and Small Business Management (BESBM),

- $\quad$ Bachelor of Procurement and Supply Management (BPSM),

- $\quad$ Bachelor of Leisure in Hospitality Management (BLHM),

- $\quad$ Bachelor of Office and Information Management (BOIM),

- $\quad$ Bachelor of Business Computing (BBC) and,

- $\quad$ Bachelor of Commerce (BCOM).

The main data were collected in July - August 2010. Only 346 students (21 percent) cooperated and responded to the survey. The data screening process left us with 284 usable observations for further analysis. Table 1 presents the distribution of the sample by gender and age of the respondents.

Table 1: Sample characteristics

\begin{tabular}{lll}
\hline Variable/values $\mathbf{( N = 2 8 7 )}$ & Freq & $\mathbf{\%}$ \\
\hline Gender of respondents & & \\
Female & 170 & 59.2 \\
Male & 117 & 40.8 \\
Age of respondents & & \\
$18-28$ years & 265 & 92 \\
$29-39$ years & 18 & 6.3 \\
40 - 50 years & 2 & 1 \\
above 50 years & 0 & 0 \\
\hline
\end{tabular}

It is evident that majority of the respondents were female (59\%), and majority belonged to the age bracket between $18-28$ years.

Measurement of variables: Learning environment was conceptualised to consist of lecturer, lecturing and classroom characteristics.

- $\quad$ Lecturer characteristics - question items measuring lecturer characteristics were adapted from studies of Hanushek (1971), Uusimaki and Nason (2004), Beswick (2006), Wilkins and Brand(2004) and Swan, Bell, Phillips and Shannon (2000) item questions were generated to capture lecturer characteristics such as lecturer's attitude, facilitation of mathematical thinking, facilitation of learning, course organization, effective assessment.

- $\quad$ Lecturing characteristics - item questions were generated to capture lecturing characteristics such as learning centred approach and teaching centered approach. These were adapted from scales used by Anderson (2005), Townsend et al. (1998), Higgins (1997) and Pearce et al. (1999).

- $\quad$ Classroom characteristics - item questions were generated to capture classroom characteristics such as environment (lighting and physical condition) and class size. (Overall Cronbach's alpha coefficient for learning environment $=.84$ ).

Students' attitudes - Students' attitudes towards quantitative course units was measured by guidelines developed by Fishbein and Ajzen (1975) and Ajzen (1991). From the item questions, one adjective either positive or negative was chosen, and the students matched with what suited them. (Cronbach's alpha coefficient $=.67$ ).

Performance in quantitative course units was measured by instrument used by Kingdon (2006) and Rockoff (2003). The items generated were in terms of self evaluation and individual productivity in the quantitative course units. The individual productivity was measured in terms of scores (in tests and exams) and number of retakes. (Cronbach's alpha coefficient $=.82$ ).

Data analysis and procedure: Data analysis process started with data management, which involved checking for completeness, consistency and accuracy of responses using the Statistical Package for Social Sciences (SPSS) version 19. The process retained 287 usable observations. Descriptive analyses were performed to describe the demographic characteristics of the study participants and variables (Table 1 
above). Zero order correlations between the dependent variables and the independent variables are presented in table 2. A hierarchical regression was employed to establish the contribution of each predictor variable in the equation. The results are presented next.

\section{Results}

Correlations: Table 2 presents a zero order correlation results showing the relationships between the study variables.

Table 2: Correlations

\begin{tabular}{llll}
\hline & Learning environment & Attitude & Performance \\
\hline Learning environment & 1.00 & & \\
Attitude & $.157^{*}$ & 1.00 & \\
Performance & $.265^{* *}$ & $.221^{* *}$ & 1.00 \\
\hline
\end{tabular}

xxCorrelation is significant at the 0.01 level ( 2 tailed)

xCorrelation is significant at the 0.05 level (2 tailed)

The results show that there is a positive and significant relationship between learning environment and performance in quantitative courses $(r=.265, p<.05)$, which implies that changes in learning environment are associated with positive changes in performance. The results also show that there is a positive and significant relationship between students' attitude and performance in quantitative courses $(r=.221, p<.05)$.

Regression Analysis: A hierarchical regression analysis was conducted to determine the contribution effects of learning environment and attitude on performance in quantitative course units. The results are presented in table 3.

Table 3: Hierarchical regression

\begin{tabular}{lllllll}
\hline & Model 1 & & Model 2 & \multicolumn{3}{c}{ Model 3 } \\
Variable & B & SE & B & SE & B & SE \\
\hline Constant & $4.278^{* *}$ & .207 & $3.660^{* *}$ & .246 & $3.074^{* *}$ & .299 \\
Gender & .059 & .096 & -.012 & .094 & -.040 & .093 \\
Age & -.146 & .150 & -.093 & .146 & -.063 & .144 \\
Learning Environment & & & $.208^{* *}$ & .048 & $.188^{* *}$ & .047 \\
Attitude & & & & $.223^{* *}$ & .067 \\
$\mathrm{R}$ & .066 & & .258 & & .320 & \\
$\mathrm{R}^{2}$ & .004 & & .067 & & .102 & \\
Adj R & -.003 & & .057 & & .090 & .036 \\
$\mathrm{R}^{2}$ Change & & .062 & & 11.13 & \\
F Change & & 18.80 & & .000 & \\
Sig F Change & & .000 & & & \\
\hline
\end{tabular}

${ }^{*}$ Significant at the 0.01 level $(p<.001)$

The following regression equations define the models in the table above.

Model 1: $\quad$ Perf $=\beta_{0}+\beta_{1} G+\beta_{2} A+\varepsilon$

Model 2: $\quad$ Perf $=\beta_{0}+\beta_{1} G+\beta_{2} A+\beta_{3} L E+\varepsilon$

Model 3: $\quad$ Perf $=\beta_{0}+\beta_{1} G+\beta_{2} A+\beta_{3} L E+\beta_{4} A T+\varepsilon$

Where: $\quad$ Perf $=$ Performance in quantitative course units

$\beta_{0}$ - is a constant

$\beta_{1} \mathrm{G}-$ is the unstandardised $\mathrm{B}$ coefficient of gender

$\beta_{2} \mathrm{~A}$ - is the unstandardised $\mathrm{B}$ coefficient of age

$\beta_{3} \mathrm{LE}$ - is the unstandardised B coefficient of Learning Environment 
$\beta_{4} \mathrm{AT}$ - is the unstandardised B coefficient of Students' attitude

$\varepsilon$ is the error term

The results in table 3 indicate that in Model 1, the control variables (gender and age) have an insignificant explanatory power of $0.4 \%$. This seems to suggest that the effect of gender and age on performance in quantitative course units is inconsequential. Model 2 shows that the addition of learning environment to the equation, accounts for an extra $6 \%$ of the variance explained by the model. The model also reveals a statistically significant relationship between learning environment and performance ( $\mathrm{f} \Delta=18.80 ; \mathrm{p}<.001$ ). The addition of attitude in Model 3, reveals an extra $4 \%$ of variability in performance ( $\mathrm{f} \Delta=11.13, \mathrm{p}<.001)$. More so, there is a positive and significant relationship between attitude and performance of quantitative course units. Lastly, the variables entered in the regression model explain an overall of $10 \%$ of the variance in performance in quantitative course units.

Discussion: The result on objective 1 implies that learning environment and performance in quantitative courses are closely associated. This is true because an environment characterised by good lecturer characteristics, student centred teaching method and good physical conditions of a classroom will enhance learning. This is in agreement with Afe (2001) who argues that teachers have influence on students' academic achievement hence play a crucial role in performance. Similarly, Goldhaber (2002) and Sanders (2000) state that students' performance depend on teachers' characteristics such as inspiring students, being approachable and displaying enthusiasm. This implies that lecturers should provide insights and understanding of mathematical topics to students of varying backgrounds, effectively show a variety of applications to students, inspires students to be interested in problem solving and assists students in becoming independent learners. This will go a long way in facilitating mathematical thinking and learning. The results on objective 2 imply that attitude and performance in quantitative courses are positively correlated. This provides empirical evidence indicating that improved performance in quantitative course units requires the right attitude. The finding means when students envy those around them that perform well, feel inferior, anxious and worry about quantitative course units, this kind of attitude makes them dislike the courses. This in turn deters their efforts and therefore leads to poor performance, and vice versa. The study finding is in agreement with Olatoye (2002) who stated that students attitude towards science have significant direct effect on student achievement in the subject. The finding also provides support for the theoretical underpinnings of the theory of reasoned action, which argues that people's actions are determined by their attitude (Fishbein \& Ajzen, 2010).

On analysing the results in Model 3 (table 3), it is evident that when attitude is introduced in the equation, it takes away a significant part of the predictive power of learning environment. This finding links well with the theory of planned behavior (Ajzen, 1991) which argues that, when people perceive constraints of intended behaviour, perceived behaviour control (promoters/inhibitors of behaviour), could help explain the behaviour in question. Clearly, when attitudes are strong, perceived behaviour control may have little direct effect on actual behaviour. This is true because part of the effect of perceived behaviour control is translated through attitude. Therefore, suggesting that when students' level of anxiety reduces, they are likely to evaluate problem solving in a favorable light. This in turn, will boost their attitude, and consequently stimulate them to undertake the various exercises in computational subjects and improve subsequent performance. Accordingly, in view of the fact that evaluative judgment takes precedence in behaviour, one cannot completely divorce attitude from academic achievement. Based on the findings and theoretical assertions it can be argued that learning environment and attitude are true drivers of performance in quantitative courses.

\section{Conclusion and implications}

The findings and discussion above leads to the conclusion that learning environment and students' attitude influence performance in quantitative course units. From the theoretical perspective, the key contribution this study makes, relates to the observation earlier made that there has been insufficient knowledge in the empirical research focusing on factors explaining performance in quantitative courses at university level. In this regard, this study extends the predominantly mathematics studies to other quantitative courses at university level. Future studies need to replicate the findings of this study in different contexts to test the robustness of the model. At managerial level, the study provides empirical evidence indicating students' 
attitude as a strong predictor of performance in quantitative courses. In addition, an enabling environment is closely linked to right attitude. Therefore, management of universities should consider these factors when determining possible changes to enhance students' performance. The study limitations can be seen as fruitful avenues for future research under the same theme. Firstly, this study lacks cross-validation. The extant literature is replete with studies on factors explaining performance in mathematics amongst college students. Consequently, the limited literature available, especially in a developing country context, deprived the study of the opportunity to cross-validate the present study findings. Future studies should be conducted to confirm these results. Secondly, a cross-sectional survey design was employed and thus, the study is limited to a particular occasion of measurement. Given that perceptions and beliefs change over time, there is need for a longitudinal study. In addition, the approach did not allow making clear causal attributions for the observed relationships. Therefore, the results must be interpreted with caution. Thirdly, the study concentrated on learning environment and students' attitude as predictors of performance of in quantitative courses. Future studies should investigate the effect of other factors such as social norms, self-efficacy and socialisation. By incorporating the motivational factors, a comprehensive model may be developed to explain performance in quantitative courses in universities. Lastly, the study focused on MUBS students, therefore further studies should corroborate the current study findings with experiences in other universities in Uganda.

\section{References}

Afe, J. O. (2001). Reflections on Becoming a Teacher and the Challenges of Teacher Education. Inaugural Lecture Series 64. Benin City: University of Benin, Nigeria.

Anderson, J. (2005). The relationship between student perceptions of team dynamics and simulation game outcomes: an individual-level analysis. Journal of Education for Business, 9, 85-90.

Arbaugh, J. (2000). An exploratory study of the effects of gender on student learning and class participation in an Internet-based MBA course. Management Learning, 31(4), 503-519.

Ajzen, I. (1991). The Theory of Planned Behaviour. Organizational Behaviour and Human Decision Processes, $50,179-211$.

Barnard, W. M. (2004). Parent involvement in elementary school and educational attainment educational attainment. Children and Youth Services Review. Children and Youth Services Review, 26, 39-62.

Beswick, K. (2006). Changes in pre-service teachers' attitudes and beliefs: the net impact of two mathematics education units and intervening experiences. School Science and Mathematics, 106(1), 36-47.

Beswick, K. (2007). Teachers' beliefs that matter in secondary mathematics classrooms. Educational Studies in Mathematics, 65(1), 95.

Darling-Hammond, L. (2000) New Standards and old equalities: School reform and the education of African American students. The Journal of Negro Education, 69(4), 263-287.

Felder, R. M., Felder, G. N. \& Dietz, E. J. (2002). The effects of personality type on engineering student performance and attitudes. Journal of Engineering Education, 87(18), 469-480

Fishbein, M. \& Ajzen, I. (1975). Belief, attitude, intention, and behavior: An introduction to theory and research. Reading, MA: Addison-Wesley.

Fishbein, M. \& Ajzen, I. (2010). Predicting and changing behavior: The reasoned action approach. New York: Psychology Press.

Fisher, K. (2000). Building Better Outcomes. The Impact of School Infrastructure on Student Outcomes and Behaviour. Schools Issues Digest, Department of Education, Training and Youth Affairs, Australian Government.

Goldhaber, D. (2002). The mystery of good teaching: Surveying the evidence on student achievement and teachers' characteristics. Education Next, 2(1), 50-55. The Hoover Institution.

Hanushek, E. (1971). Teacher Characteristics and Gains in Student Achievement: Estimation Using Micro Data. The American Economic Review, 61(2), 280-288. Accessed on 20/05/2010, http://www.jstor.org/stable/1817003.

Hanushek, E. (2010). The economic value of teacher quality. The Economics of Education Review, 30(3).

Higgins, E. T. (1997). Beyond pleasure and pain. American Psychologist, 52, 1280-1300.

Kingdon, G. G. (2006). Teacher characteristics and student performance in India: A pupil fixed effects approach. GPRG-WPS-059, http://www.gprg.org/

Krejcie, R. \& Morgan, D. (1970). Determining sample size for research activities. Educational and Psychological Measurements, 30, 607-610. 
Maliki, A. E., Ngban, A. N., \& Ibu, J. E. (2009). Analysis of Students' Performance in Junior Secondary School mathematics examination in Bayelsa State of Nigeria. Student Communication Science, 3(2), 131-134.

Martins, P. \& Walker, I. (2006). Student Achievement and University Classes: Effects of Attendance, Size, Peers, and Teachers. IZA, Discussion paper no 2490.

Mohidin R., Jaidi, F., Sang, L. T. \& Osman, Z. (2009). Effective teaching methods and lecturer characteristics a study on accounting students at Universiti Malaysia Sabah. European Journal of Social Sciences, 8(1), 21- 29.

Olatoye, R. A. (2002). A Causal Model of School Factors as Determinants of Science Achievement in Lagos State Secondary Schools. An Unpublished Ph.D. Thesis, Univeristy of Ibadan, Ibadan.

Patriciah, W. W. \& Johnson, M. C. (2007). Effects of Mastery Learning Approach on Secondary School Students' Physics Achievement. Eurasia Journal of Mathematics, Science and Technology Education, 4(3), 293302.

Pearce, K., Lungren, M. \& Wince, A. (1999). The effects of curriculum practices on first graders' attitudes, activity preference, and achievements in mathematics. Education, 119(1), 82-90.

Popham, W. (2005). Students' attitudes count. Educational Leadership, 2, 84-85.

Pokay, P. \& Blumenfeld, P. C. (1990). Predicting achievement early and late in the semester: The role of motivation and use of learning strategies. Journal of Educational Psychology, 82, 41-50.

Roberts. G. A. (2007). The effect of extracurricular activity participation in the relationship between parent involvement and academic performance in a sample of third grade children. Retrieved from http://www.lib.utexas.edu/etd/d/2007/robertsg11186/robertsg 11186.pdf

Rockoff, J. E. (2003). The Evidence of Individual Teachers on Student Achievement: Evidence from Panel Data. Report published by the Kennedy School of Government, Harvard University, ED 475274.

Sanders, W. L. (2000). Value-added assessment from student achievement data: opportunities and hurdles. Journal of Personnel Evaluation in Education, 14(4), 329-39.

Schwartz, W. \& Hanson, K. (1992). Equal Mathematics Education for Female Students. (Report No. 78). Newton, MA: Education Development Center, Inc., Center for Equity and Cultural Diversity. ERIC/CUE Digest, 78.

Shafiq, M., Farooq, M. S., Chaudhry, A. H. \& Berhanu, G. (2011). Factors Affecting Students' Quality of Academic Performance: A Case of Secondary School Level. Journal of Quality and Technology Management, 7(2).

Stage, F. K. (2000). Making a difference in the classroom. About Campus, July/August, $29-31$.

Sternberg, R. J. \& Kaufman, J. C. (1998). Human abilities. Annual Review of Psychology, 49, 479-502.

Swan, K., Shea, P., Fredericksen, E., Pickett, A., Pelz, W. \& Maher, G. (2000). Building knowledge building communities: Consistency, contact and communication in the virtual classroom. Journal of Educational Computing Research, 23, 359-383.

Thurstone, L. L. (1928). Attitudes Can Be Measured. The American Journal of Sociology, 33(3), 529-554.

Townsend, M., Moore, D., Tuck, B. \& Wilton, K. (1998). Self-concept and anxiety in university students studying social science statistics within a co-operative learning structure. Educational Psychology, $18(1), 1-14$.

Trei, L. (2005). Student success linked to certification. Stanford Report, April 20, 2005.

Uusimaki, L. \& Nason, R. (2004). Causes underlying pre-service teachers' negative beliefs and anxieties about mathematics. Proceedings of the 28th Conference of the International Group for the Psychology of Mathematics Education, 4, 369-376.

Urquiola, M. \& Verhoogen, E. (2009). Class-size caps, sorting, and the regression discontinuity design. American Economic Review, 99(1).

Walberg, H. J. (1999). Productive teaching In H. C. Waxman \& H. J. Walberg (Eds.), New directions for teaching practice research (75-104).

Wentzel, K. R. (1998). Social Relationship and Motivation in middle School. The Role of Parents, Teachers and Peers. British Journal of Education Psychology, 68(2), 35-43.

Wilkins, M. \& Brand, D. R. (2004). Change in pre-service teachers' beliefs: An evaluation of a mathematics course. Science and Mathematics, 104, 226-232.

Wolf, S. J. \& Fraser, B. J. (2007). Learning environment, attitudes and achievement among middle-school science students using inquiry-based laboratory activities. Research in Science Education, (in press).

Yoder, J. D. \& Hachevar, C. M. (2005). Encouraging active learning can improve students' performance on examinations. Teaching of Psychology, 32(2). 